\title{
Helicobacter pylori stimulates antral mucosal reactive oxygen metabolite production in vivo
}

\author{
G R Davies, N J Simmonds, T R J Stevens, M T Sheaff, N Banatvala, I F Laurenson, \\ D R Blake, D S Rampton
}

\begin{abstract}
To determine if reactive oxygen metabolites have a pathogenic role in Helicobacter pylori ( $H$ pylori) related gastroduodenal disease, this study measured their production in antral mucosal biopsy specimens. Two related chemiluminescence techniques were used comparing $H$ pylori positive $(n=105)$ and negative patients $(n=64)$ with a similar spectrum of macroscopic disease. After chemiluminescence assays, biopsy specimens were graded histologically. Increased luminol dependent chemiluminescence (detecting reactive oxygen metabolites through peroxidase catalysed reactions) was found in $H$ pylori positive patients (median photon emission $=6.4 \times 10^{3} / \mathrm{min} / \mathrm{mg}$ wet weight $(95 \%$ confidence intervals 3.6 to 9.9 ) ) but not $H$ pylori negative cases $(-0.9(-1.3$ to -0.6$))$ $(p=0.0001)$. Similar results were found using lucigenin (which reacts directly with oxygen metabolites, particularly superoxide): (H pylori positive $0.9(0.1$ to 3.2$) ; H$ pylori negative $-1.2(-3.4$ to -0.6$))(p=0.0003)$. Chemiluminescence was greater in $H$ pylori positive compared with negative tissue when samples were grouped by equivalent macroscopic or microscopic damage. This difference was in part accounted for by a greater neutrophil infiltration in the $\boldsymbol{H}$ pylori positive mucosa, but when biopsy specimens with equivalent neutrophil infiltration could be compared directly, positive specimens gave greater chemiluminescence than negative. Smoking, drugs, and alcohol consumption had no independent effect. It is concluded that excess mucosal reactive oxygen metabolite production is associated with $\boldsymbol{H}$ pylori gastric antral infection and may be an important pathogenic mechanism. There is no evidence for reactive oxygen metabolite participation in the pathogenesis of gastric mucosal injury in cases unrelated to $\boldsymbol{H}$ pylori infection.

(Gut 1994; 35: 179-185)
\end{abstract}

Helicobacter pylori causes an acute ${ }^{1}$ followed by a chronic $^{23}$ gastritis, both characterised by a considerable neutrophil infiltrate. The infection is associated with duodenal ulceration, ${ }^{45}$ and perhaps gastric carcinoma. ${ }^{67}$ Although many potential pathogenic mechanisms have been proposed, ${ }^{89}$ there is little evidence as to which might be of importance to such $H$ pylori related disease in vivo. Potent chemotactic factors isolated from $H$ pylori culture media ${ }^{10}$ could account for the considerable mucosal inflammation induced by an organism that attaches to, but rarely invades the gastric mucosa. Reactive oxygen metabolite (ROM) production by phagocytic inflammatory cells is important for host defence against certain micro-organisms, but is not always confined intracellularly - that is, within phagosomes, and may thus contribute to host cytotoxicity." Phagocyte activation, however, is usually self limiting and the response regulated as tissue damage is repaired or bacteria eliminated.

If phagocytic inflammatory cells were attracted to, and activated in, an otherwise intact mucosa, they could be an important cause of tissue damage, rather than the response to it. ${ }^{112}$ It is plausible that $H$ pylori causes mucosal damage through such a mechanism, as both the bacteria and its soluble products have now been shown to activate human phagocytes in vitro, ${ }^{13-18}$ with associated $\mathrm{ROM}$ production.

To see if there was evidence for mucosal phagocyte activation related to $H$ pylori gastritis in vivo, we used a chemiluminescence assay to look for disease related ROM production in antral mucosal biopsy specimens from patients with $H$ pylori positive gastritis, comparing them with patients with a similar degree of gastritis, but negative for $H$ pylori.

\section{Materials and methods}

\section{PATIENTS}

Patients $(n=169)$ having routine diagnostic upper gastrointestinal endoscopy at The Royal London Hospital were selected at random for study if their gastric mucosa was macroscopically normal or had mild to moderate diffuse inflammation. Patients with gastric ulceration, severe erosive gastritis or active bleeding were excluded. Gastric antral macroscopic appearance was graded according to a modified Lanza scale, ${ }^{19}$ with each of three separate features (inflammation, erosions, and haemorrhage) given individual scores, totalled for the final grade (Table I). $H$ pylori antral infection was diagnosed in 105 patients on the basis of histology and culture, or commercial urease (CLO) test, or both; the remaining 64 were negative for infection by all three methods. The $H$ pylori positive and negative groups were well matched in relation to age, sex, smoking, alcohol consumption, and drug treatment. Two to four antral biopsy specimens were taken for ROM assay by chemiluminescence, and the same specimens used for histological assessments. Separate specimens were taken for urease test and culture. This study was approved by the Tower Hamlets Health Authority ethical committee. 
TABLE I Scoring system for macroscopic appearance of gastric antral mucosa

\begin{tabular}{|c|c|c|c|c|}
\hline \multirow[b]{2}{*}{ Feature } & \multicolumn{4}{|l|}{ Score } \\
\hline & 0 & 1 & 2 & 3 \\
\hline $\begin{array}{l}\text { Mucosal injection } \\
\text { Erosive lesions } \\
\text { Haemorrhagic lesions }\end{array}$ & $\begin{array}{l}\text { None } \\
\text { None } \\
\text { None }\end{array}$ & $\begin{array}{l}\text { Slight } \\
\text { Few small } \\
\text { Few petechiae }\end{array}$ & $\begin{array}{l}\text { Moderate } \\
\text { Intramucosal haemorrhage }\end{array}$ & Severe \\
\hline
\end{tabular}

\section{CHEMILUMINESCENCE ASSAY FOR REACTIVE} OXYGEN METABOLITES

We have previously described in detail the chemiluminescence technique used to detect ROM production in mucosal biopsy specimens. ${ }^{2021}$ Chemiluminescence probes react with ROM, forming excited state molecules that relax with the emission of light: the photon emission is directly related to ROM production and detected with a sensitive dual tube photomultiplier device (Packard Tri Carb 1600 CA liquid scintillation analyser). Two chemiluminescence probes were used: (1) luminol, which, in the presence of neutrophil derived myeloperoxidase, detects mainly hydrogen peroxide and hypochlorite, as the reactions of these ROM with luminol are catalysed by peroxidases ${ }^{22}$; (2) lucigenin, which reacts directly with $\mathrm{ROM}$, and is particularly sensitive to superoxide. ${ }^{23}$ Specimens from 152 patients were assayed using the luminol chemiluminescence probe, 58 using lucigenin and 41 by both methods.

Each specimen was placed separately in preoxygenated phosphate buffered saline at $\mathrm{pH} 7 \cdot 4$, and transferred to a precounted scintillation vial containing $1 \mathrm{ml}$ of $75 \mu \mathrm{mol}$ luminol or $75 \mu \mathrm{mol}$ lucigenin just before chemiluminescence assay. Sample photon emission was measured for five minutes. Each biopsy specimen chemiluminescence result was expressed as average photon emission $/ \mathrm{min} / \mathrm{mg}$ wet $\mathrm{wt} \times 10^{3}$, after subtraction of scintillation vial background ( $95 \%$ confidence intervals (CI)). Individual specimen chemiluminescence results were then averaged to give luminol or lucigenin chemiluminescence scores, or both for each patient. Negative results may occur after subtraction of scintillation vial background for specimens causing no, or little, activation of the chemiluminescence system, as addition of inactive antral biopsy tissue, in the absence of ROM production, quenches background chemiluminescence.

\section{INHIBITOR STUDIES}

To show that ROM production was the cause of the chemiluminescence seen, we used a range of antioxidants (Table II). Figure 1 shows the actions of the antioxidants. Only specimens with initially high chemiluminescence (more than 40000 counts $/ \mathrm{min} / \mathrm{specimen}$ ) were used, and only when a second specimen with similar counts was available from the same patient for the control experiment (Table II). There was no significant difference in initial sample chemiluminescence between the 27 pairs of specimens $(\mathrm{p}=0.92$, paired Student's $t$ test). Pairs of specimens from at least six different patients were used for each antioxidant. After addition of antioxidant or its control, vials were recounted for five minutes. Effects were expressed as the percentage change in chemiluminescence compared with the result obtained with the control.

Immediately after chemiluminescence assays (within two hours of obtaining the specimen) samples were dry blotted, weighed, and prepared for histological assessment.

REPEATABILITY OF CHEMILUMINESCENCE ASSAYS

This was assessed where more than one specimen was taken from the same site in the same patient, and assayed by the same chemiluminescence probe. Median (95\% confidence intervals (CI)) percentage disagreements between the highest and lowest chemiluminescence results were 18 $(-25$ to 48$)(n=87)$ for luminol chemiluminescence and 33 (13 to 87$)(n=46)$ for lucigenin chemiluminescence. This scatter was small in comparison with the differences found between patients.

\section{HISTOLOGICAL STUDIES}

Sections were coded so microscopic assessments were made blind to the chemiluminescence result and other biopsy details. Haematoxylin and eosin stained sections were prepared from formalin preserved specimens in 103 of the patients, and inflammation graded semiquantitatively (Table III). Neutrophil infiltration was scored specifically in 65 patients using an image analysis system. Three superficial fields $(\times 25$ magnification) were selected at random, and the image examined on a monitor screen. Neutrophils were individually counted on each digitised image, and scores from the three fields totalled.

\section{CULTURE AND PREPARATION OF HELICOBACTER PYLORI}

To exclude direct activation of the chemiluminescence by $H$ pylori, we added live or sonicated organisms to $75 \mu \mathrm{mol}$ luminol or $75 \mu \mathrm{mol}$ lucigenin, and measured chemiluminescence under identical conditions to those used for the

TABLE II Active and control compounds used to assess the type of reactive oxygen metabolites present in biopsy specimens

\begin{tabular}{|c|c|c|c|c|}
\hline Compound ${ }^{\star}$ & Action & $\begin{array}{l}\text { Volume:final } \\
\text { concentration }\end{array}$ & Control & $\begin{array}{l}\text { Chemiluminescence } \\
\text { probe }\end{array}$ \\
\hline Sodium azide & $\begin{array}{l}\text { Inhibitor of peroxidase enzymes and } \\
\text { therefore of hypochlorite production }\end{array}$ & $50 \mu \mathrm{l}: 10 \mathrm{mM}$ & $50 \mu \mathrm{l}$ PBS & Luminol $75 \mu \mathrm{mol}$ \\
\hline $\begin{array}{l}\mathrm{Cu} \mathrm{Zn} \text { superoxide } \\
\text { dismutase }\end{array}$ & Enzyme; catalyses removal of superoxide & $50 \mu \mathrm{l}: 300 \mathrm{U} / \mathrm{ml}$ & $\begin{array}{l}50 \mu l \text { heat inactivated } \\
\text { enzyme }\end{array}$ & Lucigenin $75 \mu \mathrm{mol}$ \\
\hline $\begin{array}{l}\text { Dimethyl sulphoxide } \\
\text { Catalase }\end{array}$ & $\begin{array}{l}\text { Scavenger of hydroxyl radicals } \\
\text { Enzyme; catalyses removal of hydrogen } \\
\text { peroxide }\end{array}$ & $\begin{array}{l}50 \mu \mathrm{l}: 5 \% \\
50 \mu \mathrm{l}: 3000 \mathrm{U} / \mathrm{ml}\end{array}$ & $\begin{array}{l}50 \mu l \text { PBS } \\
50 \mu l \text { heat inactivated } \\
\text { enzyme }\end{array}$ & $\begin{array}{l}\text { Luminol } 75 \mu \mathrm{mol} \\
\text { Luminol } 75 \mu \mathrm{mol}\end{array}$ \\
\hline
\end{tabular}

*Chemicals were obtained from Sigma Chemical Co, Dorset, UK. PBS=phosphate buffered saline. 


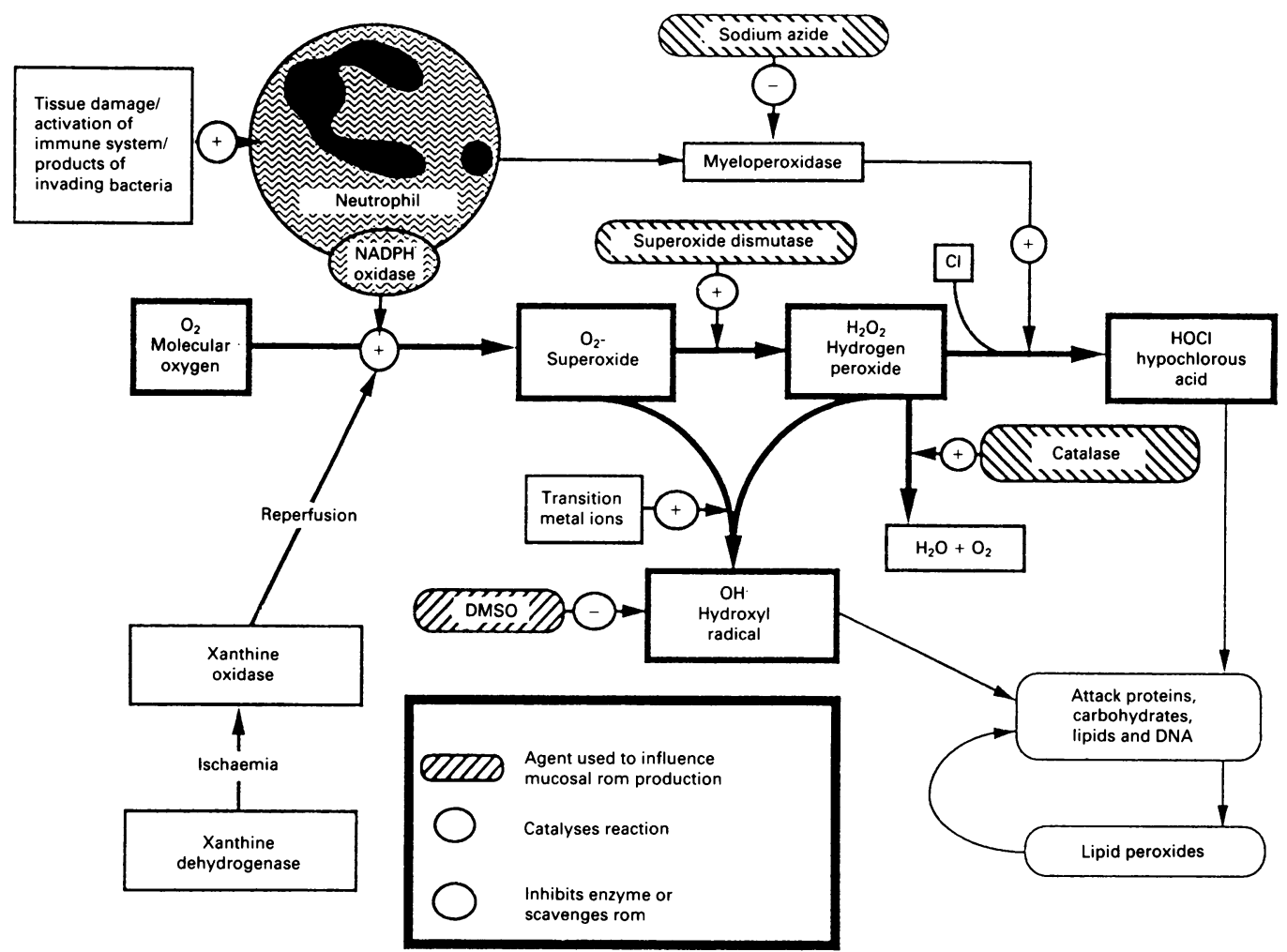

Figure 1: Sources of reactive oxygen metabolites (ROMs), their routes of metabolism, and sites of action (IIIIII) of compounds used to influence ROM production during chemiluminescence assays.

antral biopsy specimen assays. $H$ pylori were grown using standard culture techniques, ${ }^{24}$ with a medium of brucella broth plus $1 \%$ fetal calf serum. Before chemiluminescence assays, $H$ pylori was concentrated by centrifugation, washed, and resuspended in phosphate buffered saline. The colony count and purity of the final washed $H$ pylori isolate was established by microscopy and subculture using the technique of Miles and Misra. ${ }^{25}$

\section{STATISTICS}

Two tailed, non-parametric statistics were used: Kruskal-Wallis test for multiple group comparisons, Mann-Whitney U or Wilcoxon signed rank tests for two group comparisons, and Spearman's rank correlation to test for associations between variables.

\section{Results}

Luminol dependent chemiluminescence was detected in antral biopsy specimens from $H$ pylori positive patients (median $6.4 \times 10^{3}$

TABLE III Histological (haematoxylin and eosin) grading scheme for antral biopsy specimens

Grade 0 No increase in inflammatory cell` infiltrate or glandular disruption

Grade 1 Scanty inflammatory cell ${ }^{\star}$ infiltrate with no glandular disruption

Grade 2 Moderate to severe inflammatory cell ${ }^{\star}$ infiltrate. Glandular architecture is intact but may show mild regenerative changes

Grade 3 Severe inflammatory cell ${ }^{\star}$ infiltrate with considerable glandular disruption, marked regenerative changes or ulceration

^Acute or chronic, or both inflammatory cells. photons/min/mg (95\% CI 3.6 to 9.9 ), $\mathrm{n}=98$ ) but not $H$ pylori negative, where biopsy specimen chemiluminescence rarely exceeded background counts $(-0.9(-1.3$ to -0.6$), \mathrm{n}=54)(\mathrm{p}=0.0001$, $H$ pylori positive $v H$ pylori negative). Using the lucigenin probe, chemiluminescence was also detected in $H$ pylori positive tissue $(0.9)(0 \cdot 1$ to $3 \cdot 2), \mathrm{n}=35)$ but not $H$ pylori negative $(-1 \cdot 2$ $(-3.4$ to -0.6$), \mathrm{n}=23)(\mathrm{p}=0.0003)$.

Where luminol and lucigenin amplified chemiluminescence was positive in specimens from the same area in the same patient, results were positively related (Spearman's $r=+0.83$, $\mathrm{p}<0.0006, \mathrm{n}=18$ ) (Fig 2). Photon emission with luminol was higher in all cases.

EFFECT OF INHIBITORS, ENZYMES, AND REACTIVE OXYGEN METABOLITE SCAVENGERS

Figure 3 summarises the results. Chemiluminescence was considerably inhibited by addition of sodium azide, which inhibits neutrophil myeloperoxidase. There were smaller, but significant decreases with catalase (which breaks down hydrogen peroxide), dimethyl sulphoxide (a hydroxyl radical scavenger), and $\mathrm{Cu} \mathrm{Zn}$ superoxide dismutase (Sigma, UK) (which converts superoxide to hydrogen peroxide and oxygen).

\section{SUBGROUP ANALYSIS BY LANZA SCORE}

Within each grade of macroscopic damage, $H$ pylori positive biopsy specimens gave more luminol dependent chemiluminescence than $H$ pylori negative $(\mathrm{p}=0.0001$ Kruskal Wallis) (Fig 4, Table IV). In the $H$ pylori negative group, none of the macroscopic disease groups had chemiluminescence results significantly differ- 

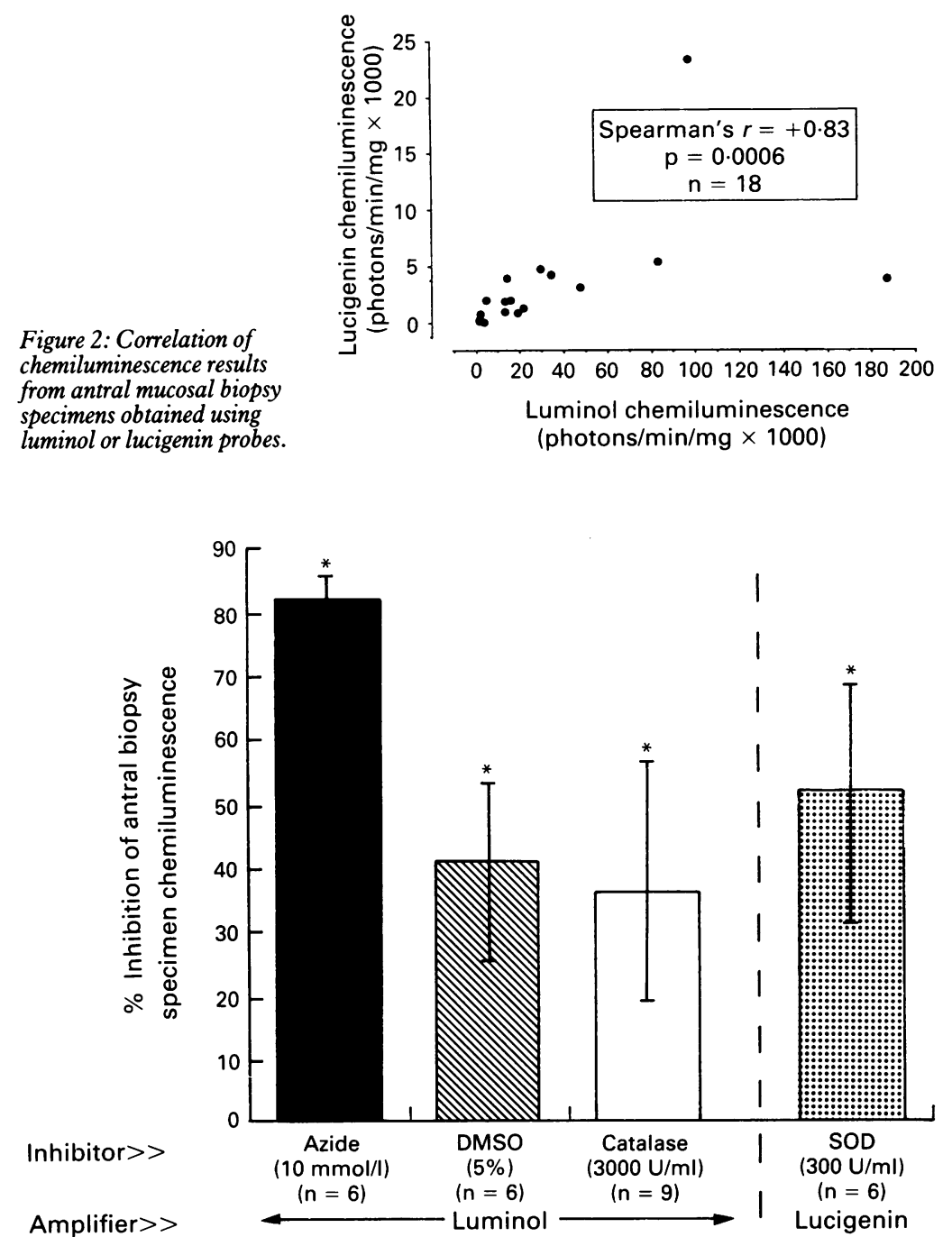

${ }^{*} p<0.05$ compared with control (Wilcoxon)

Figure 3: Median (95\% confidence intervals) percentage inhibition of antral mucosal biopsy specimen chemiluminescence with inhibitors, scavengers, and enzymes affecting reactive oxygen metabolite production. $D M S O=$ dimethyl sulphoxide, $S O D=$ superoxide dismutase.

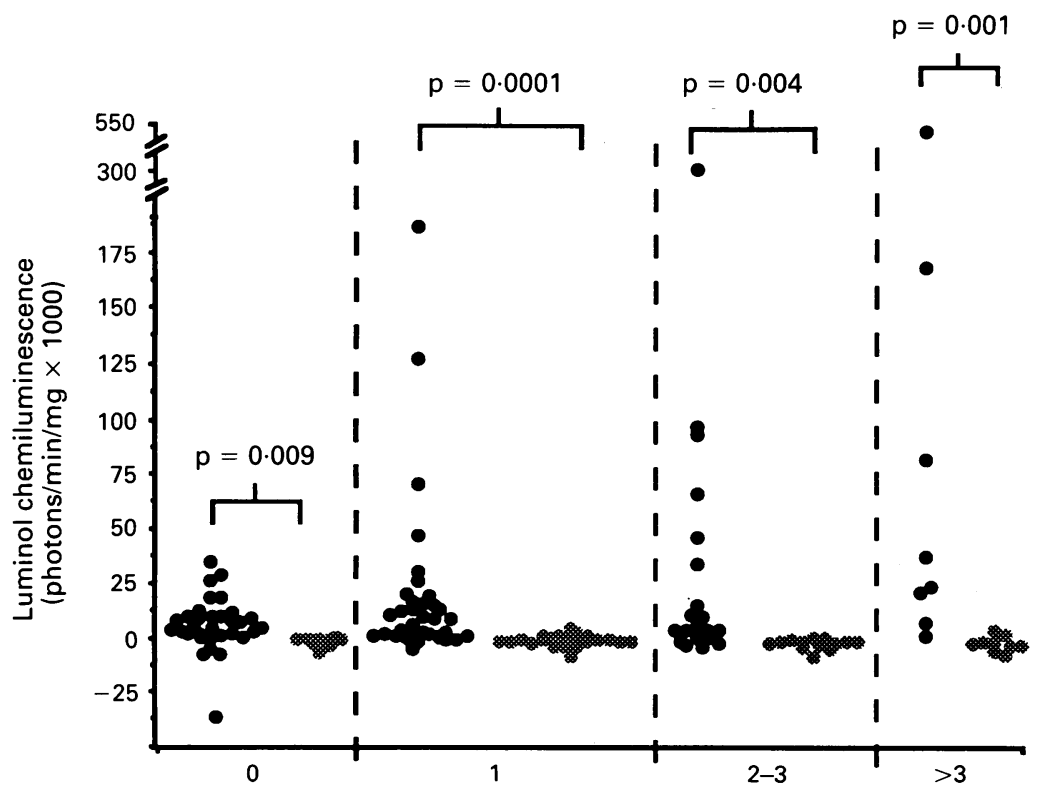

Macroscopic (Lanza score) grade of $\mathrm{H}$ pylori positive $(\bullet)$ and negative $(\bullet)$ biopsy specimens

Figure 4: Antral mucosal biopsy specimen chemiluminescence: comparison of $\mathrm{H}$ pylori positive and negative cases by modified Lanza macroscopic grade, detailed in Table II. ent to tissue with no visible damage (Lanza grade 0$)$. In the $H$ pylori positive specimens, the differences between luminol chemiluminescence in the four groups were significant $(p=0.03$ Kruskal-Wallis), and luminol chemiluminescence was weakly positively correlated with the actual Lanza score (Spearman's $r=+0 \cdot 2$, $p=0.05)$. There were no relations between the macroscopic damage and luminol chemiluminescence in the $H$ pylori negative tissue.

A similar trend for higher chemiluminescence in $H$ pylori positive tissue in each macroscopic group was also found with lucigenin, although the chemiluminescence response was much weaker and sample numbers smaller, and this trend reached significance in only one group. Table IV contrasts the luminol and lucigenin results.

SUBGROUP ANALYSIS BY MICROSCOPIC GRADING OF MUCOSAL INFLAMMATION AND DAMAGE

In samples with equivalent degrees of mucosal inflammation and damage assessed microscopically, $H$ pylori positive specimens produced more luminol dependent chemiluminescence than $H$ pylori negative $(\mathrm{p}=0.0001$ Kruskal-Wallis) (Table V). Microscopically normal specimens from $H$ pylori positive patients did not have increased chemiluminescence. The differences between the four groups in the $H$ pylori positive cases were highly significant $(\mathrm{p}=0.0002$, Kruskal-Wallis), whereas increasing mucosal inflammation and chemiluminescence was unrelated in $H$ pylori negative tissue ( $\mathrm{p}=0.63$ ).

A higher luminol chemiluminescence result was associated with a higher microscopic damage score in $H$ pylori positive cases (Spearman's $r=+0 \cdot 6, \mathrm{p}=0 \cdot 0001$ ) but not $H$ pylori negative (Spearman's $r=+0 \cdot 2, \mathrm{p}=0 \cdot 17$ ).

\section{SUBGROUP ANALYSIS BY NEUTROPHIL}

INFILTRATION

When specimens were grouped by numbers of neutrophils present in three randomly sampled fields, there was little overlap between $H$ pylori positive and $H$ pylori negative tissue (Table VI). Because neutrophil scores were low in $H$ pylori negative specimens, comparison between $H$ pylori positive and negative tissue with similar numbers of neutrophils was possible in only one subgroup, where chemiluminescence was significantly higher in the $H$ pylori positive patients $(p=0 \cdot 05)$. Chemiluminescence was positively correlated with the neutrophil score in the $H$ pylori positive specimens (Spearman's $r=$ $+0.5, \mathrm{p}=0.003)$, but not in the $H$ pylori negative specimens (Spearman's $r=+0 \cdot 4, \mathrm{p}=0 \cdot 1$ ).

\section{EFFECTS OF OTHER PATIENT FACTORS}

The influence of the following factors on antral mucosal chemiluminescence production was assessed: age, sex, smoking, alcohol consumption, severity of coexisting duodenal disease; and use of $\mathrm{H}_{2}$ blockers, omeprazole, non-steroidal anti-inflammatory drugs or iron. None had any independent influence on chemiluminescence, 
TABLE IV Luminol and lucigenin chemiluminescence from antral biopsy specimens according to Helicobacter pylori state and to macroscopic grading

\begin{tabular}{|c|c|c|c|c|}
\hline \multirow[b]{2}{*}{ Lanza score } & \multicolumn{2}{|c|}{ Luminol ( $75 \mu \mathrm{mol})$ chemiluminescence $\dagger$} & \multicolumn{2}{|c|}{ Lucigenin $(75 \mu \mathrm{mol})$ chemiluminescence $\dagger$} \\
\hline & H pylori+ & H pylori- & H pylori + & H pylori- \\
\hline 0 & $\begin{array}{c}5 \cdot 5^{\star \star}(n=32) \\
(2 \cdot 0 \text { to } 9 \cdot 6)\end{array}$ & $\begin{array}{l}-0.4(n=9) \\
(-3.3 \text { to }-0.3)\end{array}$ & $\begin{array}{l}0.9(n=7) \\
(-3.4 \text { to } 10 \cdot 2)\end{array}$ & $-6 \cdot 1(n=1)$ \\
\hline 1 & $\begin{array}{c}5 \cdot 6^{\star \star \star}(n=38) \\
(1 \cdot 8 \text { to } 13 \cdot 1)\end{array}$ & $\begin{array}{l}-0.7(n=23) \\
\quad(-1 \cdot 1 \text { to }-0.3)\end{array}$ & $\begin{array}{c}1.35(n=16) \\
(-0.1 \text { to } 3.9)\end{array}$ & $\begin{array}{l}-0.6(n=8) \\
\quad(-3.6 \text { to } 8.5)\end{array}$ \\
\hline $2-3$ & $\begin{array}{c}5 \cdot 1^{\star \star \star}(\mathrm{n}=20) \\
(0 \cdot 9 \text { to } 34 \cdot 3)\end{array}$ & $\begin{array}{l}-1 \cdot 5(n=12) \\
(-5 \cdot 4 \text { to } 2 \cdot 4)\end{array}$ & $\begin{array}{c}1 \cdot 9^{\star}(n=7) \\
(-1 \cdot 4 \text { to } 23 \cdot 4)\end{array}$ & $\begin{array}{l}-1 \cdot 6(n=8) \\
(-8 \cdot 3 \text { to }-0 \cdot 1)\end{array}$ \\
\hline$>3$ & $\begin{array}{l}31 \cdot 0^{\star \star \star}(\mathrm{n}=8) \\
(7 \cdot 9 \text { to } 168 \cdot 70)\end{array}$ & $\begin{array}{l}-1.7(n=9) \\
\quad(-5.4 \text { to } 2.35)\end{array}$ & $\begin{array}{l}1 \cdot 3(n=5) \\
(-5 \cdot 8 \text { to } 10 \cdot 4)\end{array}$ & $\begin{array}{l}-1 \cdot 6(n=6) \\
\quad(-7 \cdot 2 \text { to } 3 \cdot 3)\end{array}$ \\
\hline
\end{tabular}

${ }^{\star} \mathrm{p}<0.05,{ }^{\star \star} \mathrm{p}<0.01,{ }^{\star \star \star} \mathrm{p}<0.001$ compared with $H$ pylori negative tissue assessed with the same chemiluminescence probe. + Results are median background corrected photon emission $\times 10^{3} / \mathrm{min} / \mathrm{mg}$ (number of patients) with $95 \%$ confidence intervals in parentheses below.

either in the group as a whole or the $H$ pylori positive and $H$ pylori negative subgroups.

\section{EFFECT OF HELICOBACTER PYLORI ON}

CHEMILUMINESCENCE IN VITRO

No effect on luminol or lucigenin chemiluminescence was found when any volume of live or sonicated $H$ pylori preparation (containing initially $5 \times 10^{7}$ to $1.5 \times 10^{10}$ colony forming units/ $\mathrm{ml}$ ) was added to the scintillation vials in the absence of biopsy specimens.

\section{Discussion}

Using a chemiluminescence technique, we found evidence of excess ROM production in mucosal biopsy specimens from areas of $H$ pylori positive antral gastritis; in contrast, ROMs were not detected in $H$ pylori negative specimens. In $H$ pylori positive cases, ROM production was related directly to macroscopic and microscopic mucosal damage, and to numbers of mucosal neutrophils. These data complement previous in vitro finding ${ }^{13-18}$ that $H$ pylori and its soluble products activate ROM production from human phagocytes.

There are two possible sources of ROM in amounts of pathological importance ${ }^{26}$ (Fig 1): activated phagocytes (particularly neutrophils), and xanthine oxidase, formed from xanthine dehydrogenase during tissue ischaemia and catalysing the formation of superoxide during reperfusion. Animal data suggest that neutrophil activation is the most damaging event even in

TABLE V Luminol chemiluminescence from antral biopsy specimens according to Helicobacter pylori state and to microscopic grading of inflammation

\begin{tabular}{lll}
\hline \multirow{2}{*}{$\begin{array}{l}\text { Microscopic score } \\
\text { subgroup }\end{array}$} & \multicolumn{2}{l}{ Luminol $(75 \mu \mathrm{mol})$ chemiluminescence $\dagger$} \\
\cline { 2 - 3 } & H pylori positive $\ddagger$ & H pylori negative $\ddagger$ \\
\hline 0 & $-6 \cdot 9 \star(n=3)$ & $-1 \cdot 6(\mathrm{n}=14)$ \\
1 & $(-7 \cdot 3$ to $-3 \cdot 9)$ & $(-2 \cdot 6$ to $-0 \cdot 7)$ \\
& $1 \cdot 43^{\star}(\mathrm{n}=10)$ & $-1 \cdot 2(\mathrm{n}=13)$ \\
2 & $(-2 \cdot 4$ to $13 \cdot 8)$ & $(-3 \cdot 4$ to $-0 \cdot 3)$ \\
3 & $6 \cdot 5 \star \star(n=33)$ & $-0 \cdot 7(\mathrm{n}=7)$ \\
$(4 \cdot 1$ to $9 \cdot 8)$ & $(-4 \cdot 1$ to $4 \cdot 77)$ \\
& $20 \cdot 2^{\star}(\mathrm{n}=17)$ & $-0 \cdot 4(\mathrm{n}=1)$ \\
\hline
\end{tabular}

†Results are median background corrected photon emission $\times 10^{3} /$ $\mathrm{min} / \mathrm{mg}$, with $95 \%$ confidence intervals in parentheses below; $\mathrm{min} / \mathrm{mg}$, with $95 \%$ confidence intervals in parentheses below positive ( $\mathrm{p}=0.0002$, Kruskal-Wallis) but not $H$ pylor negative positive $(\mathrm{p}=0.0002$, Kruskal-Wallis) but not $H$ pylori negative
biopsy specimens $(\mathrm{p}=0.6),{ }^{\star} \mathrm{p}<0.05,{ }^{\star \star} \mathrm{p}<0.01$ compared with

$H$ pylori negative tissue assessed with the same chemiluminescence
biopsy secimens $(\mathrm{p}=0 \cdot 6){ }^{\star} \mathrm{p}<0.05,{ }^{\star} \mathrm{p}<0 \cdot 01$ compared with probe.
TABLE VI Luminol chemiluminescence from antral biopsy specimens according to Helicobacter pylori state and to biopsy specimen neutrophil count grading

\begin{tabular}{|c|c|c|}
\hline \multirow{2}{*}{$\begin{array}{l}\text { Neutrophils/3 } \\
\text { lower power fields }\end{array}$} & \multicolumn{2}{|c|}{ Luminol ( $75 \mu \mathrm{mol}$ ) chemiluminescence $\dagger$} \\
\hline & H pylori positive $\ddagger$ & H pylori negative $\ddagger$ \\
\hline 0 & $\begin{array}{l}1 \cdot 9 \star \star \\
(-2 \cdot 3=10) \\
(-2 \text { to } 15 \cdot 3)\end{array}$ & $\begin{array}{l}-2 \cdot 4(n=16) \\
(-5 \cdot 0 \text { to }-1 \cdot 5)\end{array}$ \\
\hline $1-10$ & $\begin{array}{c}5 \cdot 9 \star(n=17) \\
(0 \cdot 8 \text { to } 12 \cdot 7)\end{array}$ & $\begin{array}{l}-1 \cdot 0(n=7) \\
\quad(-5 \cdot 9 \text { to } 1.8)\end{array}$ \\
\hline $11-20$ & $\begin{array}{l}20 \cdot 7(n=6) \\
(3 \cdot 2 \text { to } 70 \cdot 9)\end{array}$ & \\
\hline$>20$ & $\begin{array}{l}19 \cdot 1(n=5) \\
\quad(7 \cdot 5 \text { to } 168-7)\end{array}$ & \\
\hline
\end{tabular}

†Results are median background corrected photon emission $\times 10^{3} /$ $\mathrm{min} / \mathrm{mg}$, with $95 \%$ confidence intervals in parentheses below; $\ddagger$ differences between groups were significant for the $H$ pylor $i$ positive ( $\mathrm{p}=0.02$, Kruskal-Wallis) but not $H$ pylori negative biopsy specimens $(p=0 \cdot 1$, Mann-Whitney U test $) ;{ }^{\star} p<0.05$, $\star \star \mathrm{p}<0.01$ compared with $H$ pylori negative tissue assessed with the same chemiluminescence probe.

ischaemia/reperfusion, as neutrophil depletion minimises tissue damage in such experiments. ${ }^{27}$ Superoxide is the initial oxygen radical formed in both situations, and is converted spontaneously, or under the influence of superoxide dismutase, to water and hydrogen peroxide (Fig 1). Hydrogen peroxide combines with superoxide in the presence of transition metal ions to form the toxic hydroxyl radical, or alternatively, in the presence of neutrophil derived myeloperoxidase as a catalyst, is converted to hypochlorite, another highly toxic ROM.

Chemiluminescence is a sensitive but comparatively non-specific assay for these toxic ROMs, as other oxidants may react with the probes to produce chemiluminescence. We excluded direct production of ROM from $H$ pylori, or any other activation of the chemiluminescence reaction by $H$ pylori. The results with antioxidants (Fig 3) and with the different chemiluminogenic probes, support the conclusion that the chemiluminescence system was responding, at least in the most part, to ROMs, and gives some indication of the particular ROM present. Luminol gave consistently higher results than lucigenin, which would be explained if neutrophil derived myeloperoxidase was present. In in vitro experiments, with ROM production from neutrophils receiving standard stimuli, luminol produces greater chemiluminescence than lucigenin, but only if myeloperoxidase is present to catalyse reactions of hydrogen peroxide and hypochlorite with luminol. ${ }^{22}$ In the same experimental model, lucigenin chemiluminescence can be virtually abolished by addition of superoxide dismutase, suggesting it measures primarily the superoxide ion. ${ }^{23}$ The comparatively low values of chemiluminescence with the lucigenin probe, and its inhibition by superoxide dismutase, suggest the presence of superoxide in the $H$ pylori infected specimens. The greater chemiluminescence seen with luminol compared with lucigenin in specimens from the same site, and the $80 \%$ inhibition of luminol chemiluminescence with sodium azide (a myeloperoxidase inhibitor) suggests that myeloperoxidase catalysed reactions of ROM with luminol, and thus neutrophil activation and hypochlorite production are occurring. The strong correlation in the $H$ pylori positive patients of the ROM production and quantita- 
tive neutrophil count in the same specimens is further evidence that activated neutrophils were the source of the ROM detected. Catalase and dimethyl sulphoxide produced a similar, about $40 \%$ inhibition of luminol dependent chemiluminescence, confirming the presence of hydrogen peroxide and the hydroxyl radical respectively.

A contribution by ischaemia reperfusion mechanisms to the ROM detected cannot be excluded from these data, and might explain the chemiluminescence detected in $H$ pylori positive specimens with a neutrophil score of zero (Table VI). An alternative explanation, however, is that the sampling method chosen underestimated the numbers of neutrophils present in the specimens.

The contrast between the ROM production in specimens of $H$ pylori positive and negative gastritis may well be largely explained by the greater mucosal neutrophil infiltrate in the former. There was also evidence, however, that mucosal neutrophils associated with $H$ pylori infected tissue were more activated than those associated with other causes of gastritis, as where specimens with equivalent neutrophil infiltrates could be compared, $H$ pylori positive cases had higher ROM production than $H$ pylori negative.

It could be argued that measurement of mucosal chemiluminescence is simply an indirect method of quantifying neutrophil infiltrates and, further, that ROM production is an inevitable but pathogenically irrelevant and nonspecific epiphenomenon in inflamed tissue, particularly that containing phagocytes. These arguments are discounted by our data. Firstly, in $H$ pylori negative tissue there was no correlation between chemiluminescence and neutrophil score. Secondly, as already shown, $H$ pylori positive and negative specimens with similar neutrophil scores had different chemiluminescence responses (Table VI). Lastly, macroscopically and microscopically inflamed tissue that was $H$ pylori negative did not show increased chemiluminescence (Tables IV and V, Fig 4).

Two pathogenic sequences could explain excess neutrophil derived ROM generation in antral mucosa infected by $H$ pylori. Firstly, infection could cause antral mucosal damage through mechanisms unrelated to ROM generation, for example, cytotoxin or ammonia production: the tissue damage would be a stimulus for phagocyte recruitment and activation, ${ }^{28}$ and therefore excess ROM production. Alternatively, neutrophil infiltration and activation may occur directly in response to factors derived from infecting $H$ pylori organisms, diffusing into an otherwise normal antral mucosa. We favour the second explanation, and it is supported by other experimental data: in vitro findings from six separate groups ${ }^{13-18}$ have shown that live and sonicated $H$ pylori, cell wall lipopolysaccharide extract from $H$ pylori, and cell free culture supernatant activate human phagocytes with ROM production. The nature of the activating signal is still disputed, proposals including a proteinase sensitive, heat stable, 25-35 kilodalton molecule, compatible with bacterial cell wall lipopolysaccharide, ${ }^{13}$ a small molecular weight compound with formyl-methionyl- leucyl-phenylalanine bioactive peptide like activity, ${ }^{14}$ and paf acether. ${ }^{29}$ The most recent of these in vitro studies ${ }^{18}$ showed that different strain types of $H$ pylori had differing potency for stimulation of ROM production from neutrophils: this finding may explain in part the wide range of enhanced chemiluminescence responses that we found in the various disease groups (see Fig 4).

$H$ pylori antral infection is strongly associated with duodenal ulcer disease. Although ROM have been implicated in the pathogenesis of experimental duodenal ulcer for some time, ${ }^{30} 31$ evidence in humans has only appeared in the last three years. ${ }^{2032-34}$ The hydroxyl radical scavengers, allopurinol (which also inhibits xanthine oxidase and therefore ROM production in ischaemia reperfusion) and dimethyl sulphoxide seemed to reduce the relapse rate of healed duodenal ulcers compared with cimetidine or placebo, ${ }^{32}$ and, combined with cimetidine, to improve ulcer healing compared with the antisecretory drug alone. ${ }^{33}$ Circulating lipid peroxidation products (markers of ROM mediated cell damage) were increased, and antioxidants (glutathione and plasma thiols) reduced in patients with active duodenal ulceration, values returning to normal after ulcer healing. ${ }^{34} \mathrm{We}$ recently reported increased $\mathrm{ROM}$ production in duodenal mucosal biopsy specimens from duodenal ulcer disease. ${ }^{20}$

The finding that $H$ pylori may colonise ectopic gastric mucosa in the duodenum ${ }^{35}{ }^{36}$ may provide a link between such evidence for ROM excess in duodenal ulcer disease, and the findings of this study. If $H$ pylori infection of ectopic gastric mucosa also stimulated neutrophil recruitment and activation, the localised, excessive, and cytotoxic ROM production could lead to local ulceration, particularly in the presence of other cofactors including luminal acid, bile, and pancreatic juice.

The mechanisms by which ROMs cause cell injury have recently been well reviewed, ${ }^{11}{ }^{37}$ and oxidative stress has been linked to carcinogenesis. $^{3839}$ A long term stimulation of excessive gastric mucosal ROM production in response to $H$ pylori would seem possible, and this might be relevant to the pathogenesis of gastric neoplasia, with which the organism has been associated. ${ }^{67}$ It is of related interest that the risk of carcinogenesis is lowest in populations consuming a diet rich in natural antioxidants, and that mucosal antioxidants in gastric juice fall in patients with chronic gastritis. ${ }^{40}$

The findings reported here may have therapeutic as well as pathogenic implications. Antioxidants might reduce the pathogenic effects of $H$ pylori infection, and be the only treatment option in patients with antibiotic resistant organisms. The recent finding that omeprazole inhibits neutrophil chemotaxis and activation ${ }^{41}$ may have relevance to its mode of action in $H$ pylori related disease.

In conclusion, we have shown excess ROM production in $H$ pylori infected gastric mucosa, and speculate that this is because $H$ pylor releases diffusible compounds that are capable of activating phagocytes. $H$ pylori induced ROM production could contribute both to the patho- 
genesis of antral gastritis and, through infected duodenal ectopic gastric mucosa, to duodenal ulcer disease. Proof that ROMs play a primary part in these diseases awaits the finding that specific antioxidants inhibit $H$ pylori induced antral mucosal inflammation and ROM production, and reduce the incidence of duodenal ulcer in $H$ pylori infected patients.

We are grateful for financial support from Searle Pharmaceuticals (GRD), the Hilden Charitable Fund (NIS), the National Association for Colitis and Crohn's disease (TRJS), and the Arthritis and tion for Colitis and Crohn's disea
Rheumatism Council (DRB).

Rart of these data have been presented in abstract form in Davies Part of these data have been presented in abstract form in Davies
GR, Simmonds NJ, Stevens TRJ, Grandison A, Rampton DS. Enhanced production of reactive oxygen species by gastric antral mucosa infected with Helicobacter pylori. Gut 1991; 32: A564; Davies GR, Simmonds NJ, Rampton DS. In vitro identification of reactive oxygen metabolites produced by mucosal biopsies from inflamed duodenum and $H$ pylori positive antrum. Gut 1992; 33 (suppl 1): S41

1 Morris A, Nicholson G. Ingestion of Campylobacter pyloridis causes gastritis and raised fasting gastric $\mathrm{pH}$. Am $\mathcal{f}$ Gastroenterol 1987; 82: 192-9.

2 Goodwin CS, Armstrong JA, Marshall BJ. Campylobacter pyloridis, gastritis, and peptic ulceration. 7 Clin Pathol 1986; 39: 353-65.

3 Dixon MF. Helicobacter pylori and chronic gastritis. In: Rathbone BJ, Heatley RV, eds. Helicobacter pylori and Rathbone BJ, Heatley RV, eds. Helicobacter pylor and gastroduodenal

4 Börsch GMA. Clinical significance of Campylobacter pylori. Eur 7 Gastroenterol Hepatol 1989; 1: 27-33.

5 Vaira D, Holton J, Dowsett J, Oderda G, Barbara L. Helicobacter pylori: its role in gastric disease. Dig Dis 1990; 8: 322-36.

6 Parsonnet J, Friedman GD, Vandersteen DP, Chang Y, Vogelman $\mathrm{JH}$, Orentreich $\mathrm{N}$, et al. Helicobacter pylor infection and the risk of gastric carcinoma. $N E$ Egl f Med 1991; 325: 1127-31.

7 Nomura A, Stemmermann GN, Chyou P-H, Kato I, PerezPerez GI, Blaser MJ. Helicobacter pylori infection and gastric carcinoma among Japanese Americans in Hawaii. gastric carcinoma among Japan

8 Vaira D, Holton J, Ainley C, Barbara L. Helicobacter pylori and acid-related diseases of the stomach: mechanisms of and acid-related diseases of the stomach: mechanism

9 Rathbone BJ, Heatley RV. Possible pathogenic mechanisms in Helicobacter pylori infection. In: Rathbone BJ, Heatley RV eds. Helicobacter pylori and gastroduodenal disease. 2 nd Ed. Oxford: Blackwell Scientific, 1992: 217-23.

10 Nielsen H, Andersen LP. Chemotactic activity of Helicobacter pylori sonicate for human polymorphonuclear leucocytes and monocytes. Gut 1992; 33: 738-42.

11 Halliwell B, Gutteridge JMC, Cross CE. Free radicals, antioxidants, and human disease: Where are we now? $\mathcal{f}$ Clin L $a b$ Med 1992; 119: 598-620.

12 Babior BM. Oxidants from phagocytes: agents of defense and destruction. Blood 1984; 64: 959-66.

13 Nielsen H, Andersen LP. Activation of human phagocyte oxidative metabolism by Helicobacter pylori. Gastroenterology 1992; 103: 1747-53.

14 Mooney C, Keenan J, Munster D, Wilson I, Allardyce R, Bagshaw $\mathrm{P}$, et al. Neutrophil activation by Helicobacter pylori. Gut 1991; 32: 853-7.

15 Mai UEH, Perez-Perez GI, Wahl LM, Wahl SM, Blaser MJ, Smith PD. Soluble surface proteins from Helicobacte pylori activate monocytes/macrophages by lipopolysaccharide-independent mechanisms. F Clin Invest 1991; 87: $894-900$.

16 Davies GR, Stevens TRJ, Lawrenson I, Banatvala N, Powell $M$, Rampton DS. Activation of human peripheral blood neutrophils by Helicobacter pylori in vitro. Gut 1992; 33 (suppl 1): S68
17 Suzuki M, Miura S, Suematsu M, Kurose I, Fukurijra D, Suzuki $\mathrm{H}$, et al. Helicobacter pylori enhances neutrophildependent gastric mucosal cell injury in vitro-role of monochloramine. Gastroenterology 1992; 102 (suppl): A414.

18 Rautelin H, Blomberg B, Fredlund H, Jårnerot G, Danielsson D. Incidence of Helicobacter pylori strains activating neutrophils in patients with peptic ulcer disease. Gut 1993; 34: 599-603.

19 Lanza FL. Endoscopic studies of gastric and duodenal injury after the use of ibuprofen, aspirin and other non steroidal after the use of ibuprofen, aspirin and other non ster
anti-inflammatory agents. Am $\mathcal{F}$ Med 1984; 77: 19-24.

20 Davies GR, Simmonds NJ, Stevens TRJ, Grandison A, Blake DR, Rampton DS. Mucosal reactive oxygen metabolite production in duodenal ulcer disease. Gut 1992; 33: 146772.

21 Simmonds NJ, Allen RE, Stevens TRJ, vanSomeren RNM, Blake DR, Rampton DS. Chemiluminescence assay of mucosal reactive oxygen metabolites in inflammatory bowel disease. Gastroenterology 1992; 103: 186-96.

22 Nurcombe HL, Edwards SW. Role of myeloperoxidase in intracellular and extracellular chemiluminescence of neutrophils. Ann Rheum Dis 1989; 48: 56-62.

23 Whilliams AJ, Cole PJ. The onset of polymorphonuclear leucocyte membrane-stimulated metabolic activity. Immunology 1981; 43: 733-9.

24 Tompkins DS. Isolation and characteristics of Helicobacter pylori. In: Rathbone BJ, Heatley RV, eds. Helicobacter pylori and gastroduodenal disease. 2nd Ed. Oxford: Blackwell Scientific, 1992: 19-28.

25 Miles AA, Misra SS, Irwin JO. Estimation of bacteriocidal power in blood. $\mathcal{F}$ Hyg 1938; 38: 732-49.

26 Grisham MB, Granger DN. Neutrophil-mediated mucosal injury. Role of reactive oxygen metabolites. Dig $\mathrm{Dis} \mathrm{Sci}$ 1988; 33 (suppl): 6-15S

27 Hernandez LA, Grisham MB, Twohig B, Arfors KE, Harlan JM, Granger DN. Role of neutrophils in ischaemiareperfusion-induced microvascular injury. Am $\mathcal{F}$ Physiol 1987; 253: 699-703.

28 Kozol R, Domanowski A, Jaszewski R, Czanko R, McCurdy $\mathrm{B}$, Prasad $M$, et al. Neutrophil chemotaxis in gastric mucosa. A signal-to-response comparison. Dig Dis Sci 1991; 36: $1277-80$

29 Denizot Y, Sobhani I, Rambaud J-C, Lewin M, Thomas Y, Benveniste J. Paf-acether synthesis by Helicobacter pylori. Gut 1990; 31: 1242-5.

30 Salim AS. Role of oxygen-derived free radicals in mechanism of acute and chronic duodenal ulceration in the rat. Dig Dis Sci 1990; 35: 73-9.

31 Takamasu M, Fuse Y, Kawamoto K, Kodama T, Ohishi T. Possible mechanisms of diethyldithiocarbamate-induced gastro-duodenal mucosal damage in rats. Scand $\mathcal{f}$ Gastro-duodenal mucosal damage

32 Salim AS. Oxygen-derived free radicals and the prevention of duodenal ulcer relapse: a new approach. $A m \mathcal{F} M e d S c i 1990$; 300: $1-6$.

33 Salim AS. Allopurinol and dimethyl sulfoxide improve treatment outcomes in smokers with peptic ulcer disease. $\mathcal{F} \mathrm{Lab}$ Clin Med 1992; 119: 702-9.

34 Jankowski J, Bridges AB, Scott N, Wormsley KG, Belch JF. Circulating free-radical markers and peptic ulcer disease. Eur $\mathcal{F}$ Gastroenterol Hepatol 1991; 3: 823-8.

35 Goodwin CS. Duodenal ulcer, Campylobacter pylori, and the 'leaking roof' concept. Lancet 1988; ii: 1467-9.

36 Blaser MJ. Helicobacter pylori and the pathogenesis of gastroduodenal ulceration. F Infect Dis 1990; 161:626-33.

37 Winyard $P$, Perrett D, Harris G, Blake DR. The role of toxic oxygen species in inflammation with special reference to DNA damage. In: Whicher JT, Evans SW, eds. Biochemistry of inflammation. Lancaster: Kluwer Academic, 1992: 10929 .

38 Weitzman SA, Gordon LI. Inflammation and cancer: role of phagocyte-generated oxidants in carcinogenesis. Blood 1990; 76: 655-63.

39 Trush MA, Kensler TW. An overview of the relationship between oxidative stress and chemical carcinogenesis. Free Radic Biol Med 1991; 10: 201-9.

40 Singh VN, Gaby SK. Premalignant lesions: role of antioxidant vitamins and $\beta$-carotene in risk reduction and prevention of malignant transformation. Am f Clin Nutr 199153 (suppl): 386-90S.

41 Wandall JH. Effects of omeprazole on neutrophil chemotaxis, super oxide production, degranulation, and translocation of cytochrome b -245. Gut 1992; 33: 617-21. 